\title{
Response of slowly adapting articular mechanoreceptors in the cat knee joint to alterations in intra-articular volume
}

\author{
L. WOOD AND W. R. FERRELL \\ From the Institute of Physiology, University of Glasgow
}

SUMMARY Recordings were obtained from slowly adapting mechanoreceptors innervating the posterior aspect of the cat knee joint capsule. It was observed that, with rising intra-articular volume, initially both intra-articular pressure and the neural discharge increased. This increase was dependent on the rate of fluid accumulation within the joint. However, the joint nerve discharge invariably levelled out despite increasing intra-articular volume and pressure. This suggests that there exists some limit to capsular distension in the posterior joint region beyond which fluid is diverted to other areas of the knee joint.

Joint receptors are known to play an important role in the appreciation of limb position, ${ }^{1}$ and in the reflex regulation of muscle tone. ${ }^{2}$ It has been demonstrated that these receptors exhibit 2 types of discharge: a rapidly adapting discharge responding to movement transients and a slowly adapting discharge which is maintained at static limb positions. ${ }^{3}$ The former type of discharge has been correlated with paciniform corpuscles and the latter with Ruffini endings, ${ }^{3}$ both of which are located in the stratum fibrosum of the capsule. ${ }^{5}$ Structures resembling Golgi tendon organs in the knee joint ligaments also exhibit slowly adapting responses. ${ }^{4}$

Previous investigators have also demonstrated the pressure-volume relationships in rabbit ${ }^{6}$ and human knee joints ${ }^{78}$ and how this relationship is affected by inflammatory joint diseases such as rheumatoid arthritis. $^{78}$

However, while a considerable body of knowledge has been obtained concerning the pressure-volume relationships and the properties of joint receptors, little work has been done on the effects of increased intra-articular volume and pressure changes on the discharge of slowly adapting joint receptors. Andrew and Dodt ${ }^{9}$ observed that an intra-articular injection of saline into the cat knee joint caused an increased tonic discharge from the joint nerve, but they did not quantify their results. DeAndrade et al. ${ }^{10}$ have shown that intra-articular injection of plasma into the

Accepted for publication 8 March 1983.

Correspondence to Dr W. R. Ferrell, Institute of Physiology, University of Glasgow, University Avenue, Glasgow G12 8QQ. human knee joint causes a reflex inhibition of quadriceps contraction, and they attributed this to stretching of joint receptors. Ekholm et al. ${ }^{11}$ showed that knee extensors were inhibited and flexors facilitated by increasing intra-articular pressure in the cat. More recently Grigg et al. ${ }^{12}$ have shown the effects of increased intra-articular pressure on a single joint afferent, but there has so far been no correlation with intra-articular volume. The aim of these experiments was therefore to investigate the effects of increased intra-articular volume and pressure on the discharge of slowly adapting joint receptors.

\section{Materials and methods}

Adult cats, deeply anaesthetised by intraperitoneal injection of sodium pentobarbitone $(45 \mathrm{mg} / \mathrm{kg})$ were used. Action potentials were recorded from the posterior articular nerve (PAN) which arises from the dorsal aspect of the knee joint. ${ }^{5}$ These potentials were integrated to produce a voltage level which represents the level of neural activity in the nerve and which is calibrated in impulses per second. Intra-articular infusions and pressure recordings were made via 2 cannulae inserted concentrically into the posteromedial region of the knee joint (Fig. 1).

Infusions were made via the outer cannula while intra-articular pressure was recorded via the inner cannula by an Elcomatic EM750 pressure transducer (Compliance of system $0.75 \mu \mathrm{l} / \mathrm{cm} \mathrm{H} \mathrm{H}_{2} \mathrm{o}$ ). The fluid infused into the joint was either normal saline, paraffin oil, or an infusate consisting of 3 parts DowCorning silicone oil $200 / 0 \cdot 65$ cs to 1 part paraffin oil 
which has a viscosity similar to plasma. ${ }^{6}$ Neither paraffin oil nor the infusate are absorbed across the synovial membrane, whereas saline infusions are. ${ }^{6}{ }^{13}$ Thus oil infusions enable accurate increases in intraarticular volume to be achieved. In some cases the oil infusate was stained with Sudan black in order to observe the distribution of the fluid within the capsule on postmorten dissection and to confirm the nonabsorption of the oil across the synovial membrane.

The fluid was either infused continuously at various constant rates or else was infused in $0.1 \mathrm{ml}$ steps

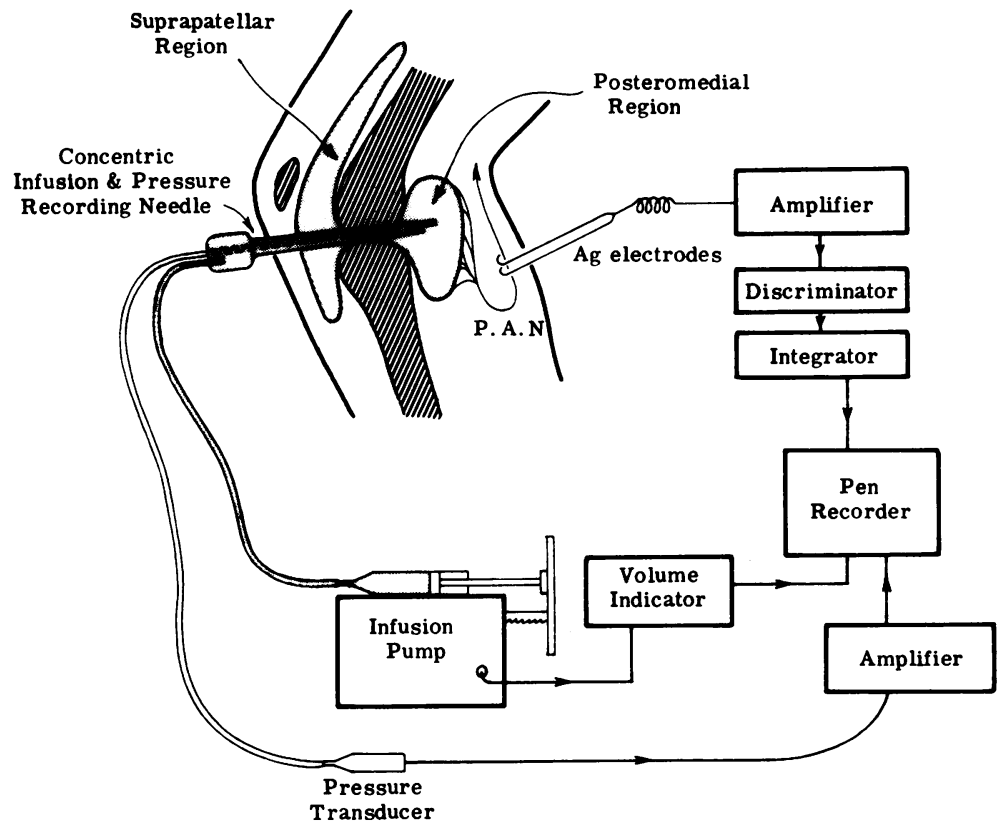

Fig. 1 Diagram of the apparatus employed in the present experiments.

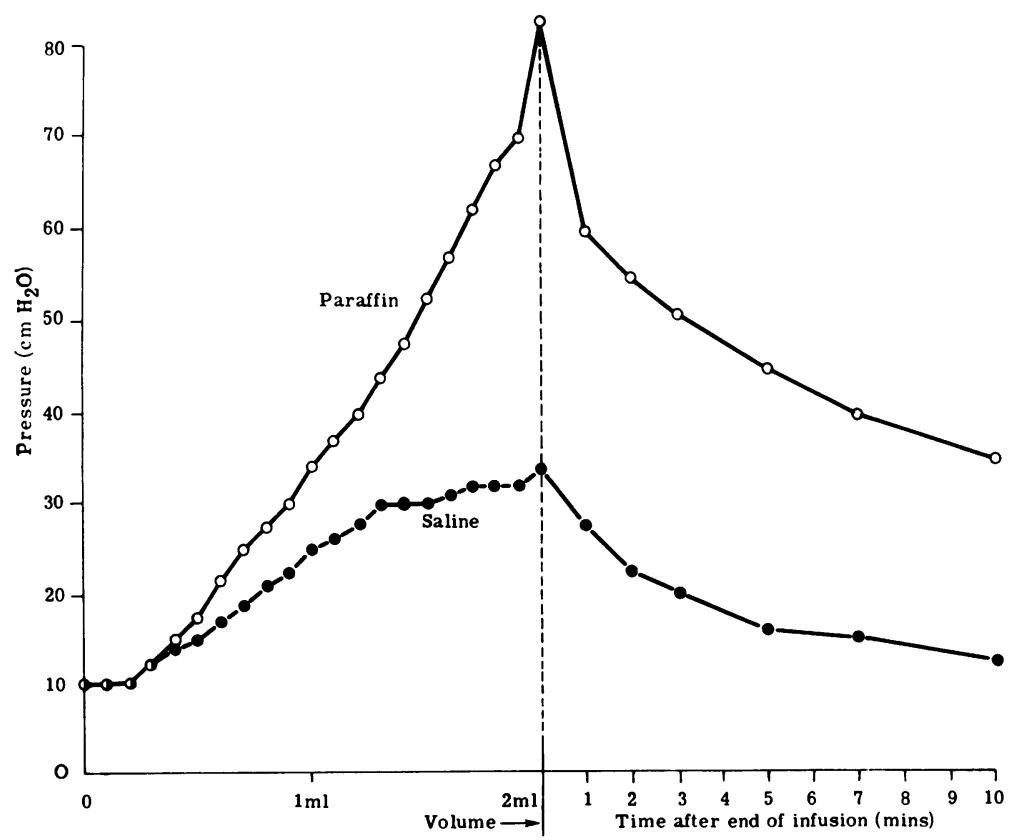

Fig. 2 Pressure-volume curves obtained by infusion at $100 \mathrm{\mu l} / \mathrm{min}$ for both saline and paraffin oil in the same knee joint. The oil infusion exhibits a rapid pressure rise during infusion and slow decline post infusion. (1 $\mathrm{cm} \mathrm{H}_{2} \mathrm{O}=0.096 \mathrm{kPa}$ ). 
every 2-3 minutes. The time interval between each step infusion was kept constant in any one experiment in order to standardise any temporal effects of stress relaxation of the capsule walls. ${ }^{6} 1415$

\section{Results}

As saline is absorbed across the synovial membrane, the results obtained with saline infusion cannot be correlated with intra-articular volume, since this would be constantly changing as absorption proceeds. In addition, as intra-articular pressure rises, the rate of saline absorption increases nonlinearly. ${ }^{13}$ This means that it would be difficult to compensate for fluid absorption by the infusion of yet more fluid.

Fig. 2 shows the pressure-volume curves obtained by a constant infusion at $100 \mu \mathrm{l} / \mathrm{min}$ for both saline and oil in the same joint and the adaptation of pressure with time after the infusion has stopped. It can be seen that the peak pressure obtained by saline infusion is much less than that obtained by oil infusion to the same volume, due to saline absorption. The pressure obtained on infusion of $2 \mathrm{ml}$ of saline corresponds to that obtained by only about $1 \mathrm{ml}$ of
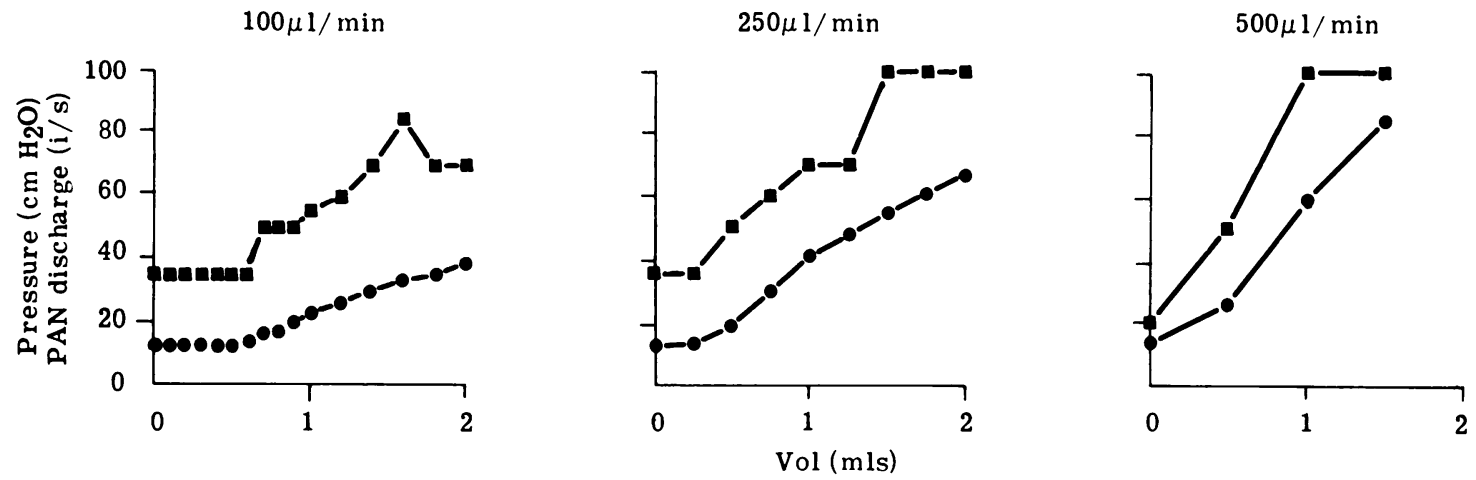

Fig. $3 \mathrm{Infusion}$ of saline at $100 \mu \mathrm{l} / \mathrm{min} 250 \mathrm{\mu l} / \mathrm{min}$ and $500 \mu \mathrm{l} / \mathrm{min}$. Time constant of integrator $0.5 \mathrm{~s}$. Both intra-articular pressure (-O) and PAN discharge ( $\square-(\mathbf{O})$ have the same scale on the ordinate.
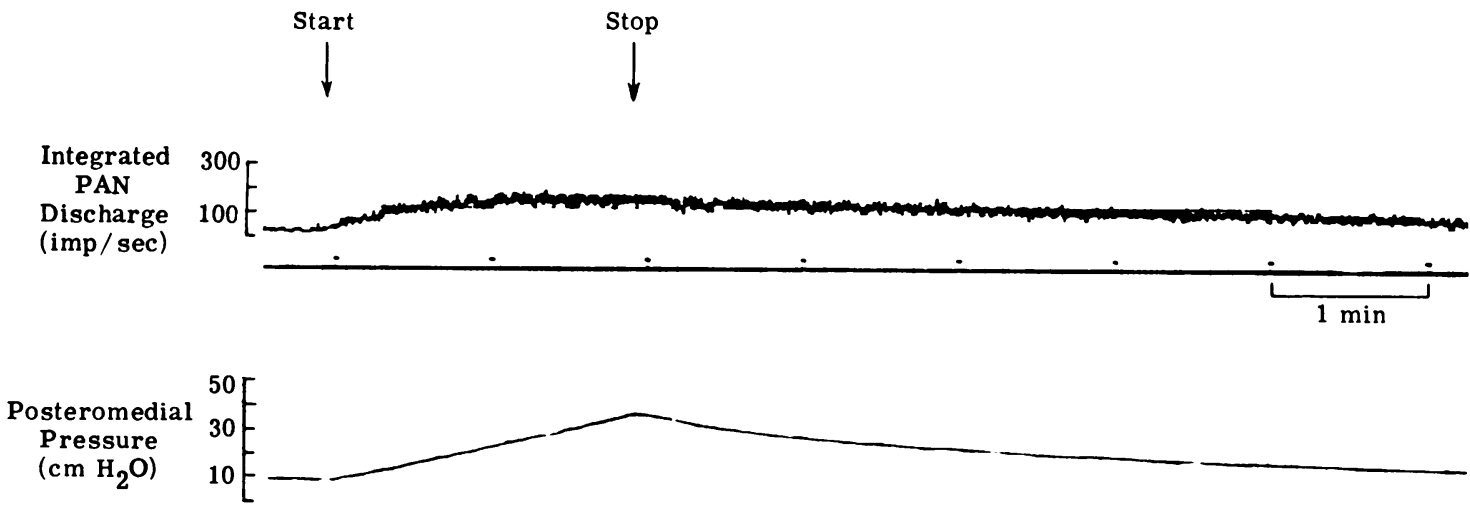

$\begin{array}{lr}\underset{\text { Infused }}{\text { Volume }} & 1.0 \\ (\mathrm{ml}) & 0.5 \\ & 0\end{array}$

Fig. 4 Infusion of paraffin oil at $250 \mu \mathrm{l} / \mathrm{min}$. Integrator time constant: $0 \cdot 5 \mathrm{~s}$. PAN discharge levels out despite continuing rise in intra-articular volume and pressure, but declines concurrently with intra-articular pressure post infusion. 


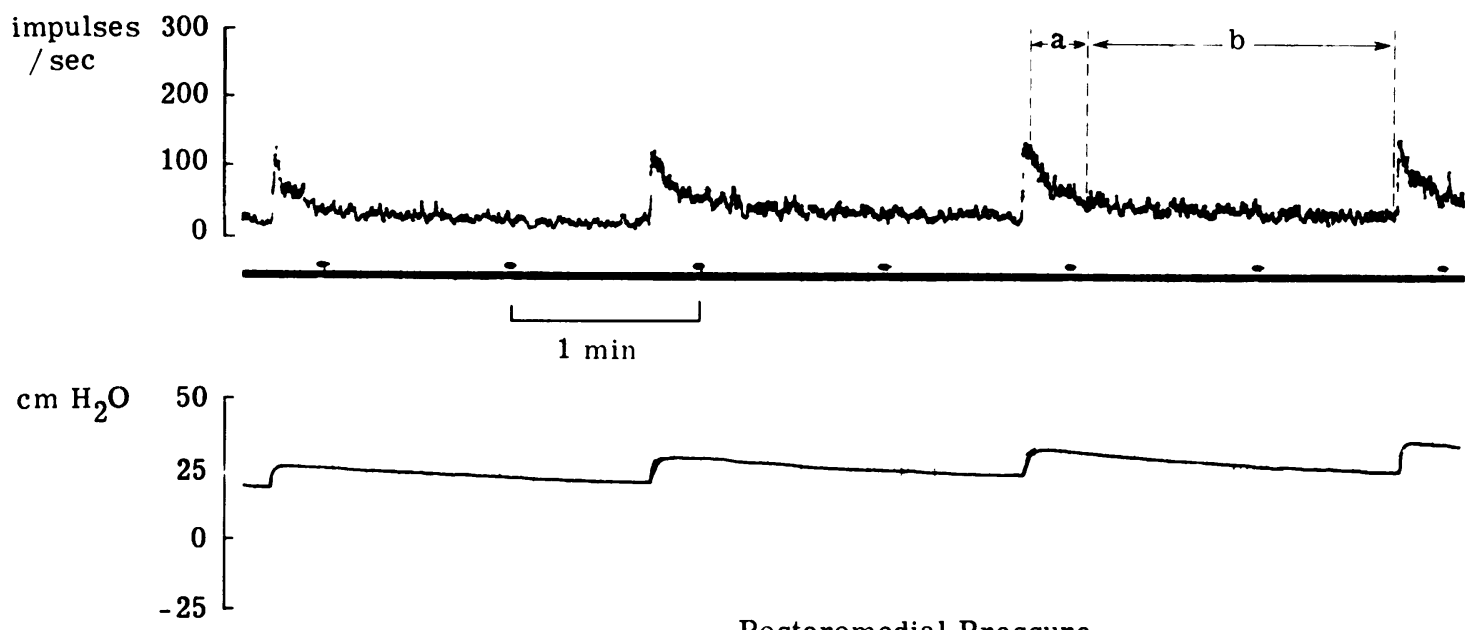

Fig. 5 Step in fusion of $\cdot 1 \mathrm{ml}$ of paraffin oil. PAN discharge post infusion shows initial rapid decline (a) followed by slower decay (b) concurrent with decreasing intra-articular pressure. Integrator time constant $0.5 \mathrm{~s}$.

oil. It can also be seen that, 10 minutes after the infusion has stopped, the pressure after saline infusion has declined almost to preinfusion levels due to a combination of stress relaxation of the capsule and saline absorption, whereas the pressure 10 minutes after the paraffin infusion is still $18 \mathrm{~cm} \mathrm{H}_{2} \mathrm{O}$ above the preinfusion level. Thus the more gradual decrease in pressure after paraffin oil infusion is solely a consequence of stress relaxation of the capsule.

Although saline infusions are of limited usefulness due to saline absorption, they can be utilised to advantage for repeated infusions at different rates, as there will be no cumulative increase in intra-articular volume. Such infusions show the dependence of both pressure and PAN discharge on the rate.

Fig. 3 shows infusions of saline at 3 different rates: $100 \mu \mathrm{l} / \mathrm{min}, 250 \mu \mathrm{l} / \mathrm{min}$, and $500 \mu \mathrm{l} / \mathrm{min}$. It can be seen that at any given volume the pressure obtained is higher if that volume is infused at a higher rate. This occurs even though there will be an increased rate of absorption of saline at higher pressures. The same kind of effect is seen with the PAN discharge; the rate of increase of PAN discharge is greater for higher rates of infusion.

Fig. 4 shows an example of the type of trace obtained with a constant infusion of oil into the joint at a rate of $250 \mu \mathrm{l} / \mathrm{min}$. It can be seen that with rising intra-articular volume both the PAN discharge and intra-articular pressure rise, and both decrease concurrently post infusion. However, it is noticeable that the PAN discharge levels out and remains constant while the infusion is proceeding and intra-articular pressure is still rising. This could be due to insufficient time for fluid to diffuse throughout the joint, and can even occur with saline infusions (Fig. 3). Therefore, step infusions were administered with a constant time interval between each step to allow such diffusion to occur.

Fig. 5 shows a typical example of the type of trace produced by $0.1 \mathrm{ml}$ step infusions of oil into the posteromedial region of the joint. The pressure exhibits an initial rapid increase during the infusion and then a gradual decay due to stress relaxation of the capsule walls, while the PAN discharge also shows an initial rapid increase, due to the increase in pressure activating the joint receptors, and then

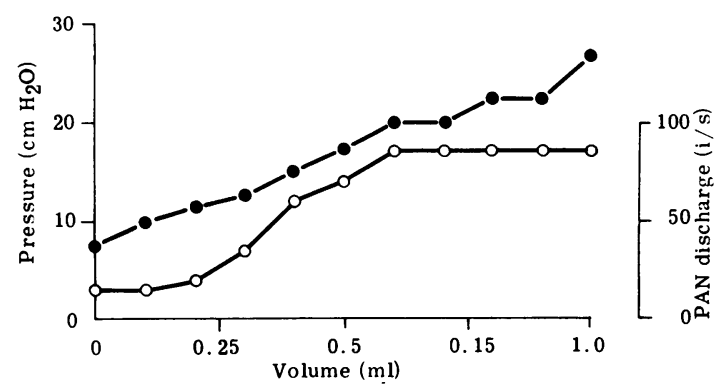

Fig. 6 Effect of step infusion of $0.1 \mathrm{ml}$ paraffin oil on posteromedial intra-articular pressure (-) and the adapted PAN discharge (O-O). The neural discharge was measured just prior to each step infusion. Integrator time constant 0.5 s. PAN discharge still exhibits plateau despite allowing time for fluid dispersal. 
adaptation to a steady level. However, this adaptation occurs in 2 stages; an initial rapid decline probably due to receptor adaptation and a slower decrease which follows the decrease in pressure.

The effect of increasing intra-articular volume on the posteromedial pressure and on the fully adapted PAN discharge is shown in Fig. 6. As intra-articular volume increases, the discharge of the joint receptors rises until a maximum plateau level is reached at about $85 \mathrm{impulses} / \mathrm{s}$. The posteromedial pressure, however, shows a monotonic rise with increasing intra-articular volume. Similar results were obtained when the lower viscosity mixture of silicone oil and paraffin was employed.

\section{Discussion}

OIL VERSUS SALINE AS INFUSATE

The pressure-volume curves obtained on continuous infusions of both saline and oil confirm that saline is absorbed across the synovial membrane while oil is not. ${ }^{13}$ At any given volume the pressure with oil as the infusate is always higher than with saline. As intraarticular volume is increased, there is an increased drive for saline absorption across the synovium, thereby reducing the pressure which can be obtained by such an infusion. Since oil is not absorbed, use of this as the infusate therefore allows accurate increases in intra-articular volume to be obtained, and true pressure changes associated with such an increase to be monitored. It can also be seen that after the infusion has stopped there is a decrease in pressure in both saline and oil curves due to stress relaxation. This is in agreement with the results of Knight and Levick, ${ }^{15}$ but, whereas the oil curve is still well above its preinfusion level after 10 minutes, the saline curve has almost returned to its preinfusion level due to the additional factor of saline absorption.

\section{RATE OF INFUSION}

The pressure-volume curves for different rates of infusion of saline (Fig. 3) show that the capsular deformation must be time dependent-i.e., at higher rates of infusion, the joint capsule cannot deform quickly enough and so a higher intra-articular pressure results. This is also reflected in the PAN discharge, where the rate of increase in the discharge is greater for a higher rate of infusion, indicating an increase in the stress applied to the receptors. The plateau phase of the PAN discharge curves for 250 $\mu \mathrm{l} / \mathrm{min}$ and $500 \mu \mathrm{l} / \mathrm{min}$ infusions may be due to the temporal limitation for capsular deformation or to fluid movement as will be discussed later. The dependence of the PAN discharge on the infusion rate may help to explain the observation that some patients with an inflammatory joint effusion may experience pain while other patients with a similar or larger volume of effusion report no discomfort. ${ }^{16}$ It may be that the time taken for such an effusion to develop is an important factor in determining pain and pressure sensation within the joint. The dependence of the pressure-volume curves on the rate of infusion of fluid is similar to that obtained by Knight and Levick ${ }^{15}$ in the rabbit knee joint.

Fig. 4 shows an example of a trace obtained with a constant infusion, and how PAN discharge increases along with the increase in pressure. After the infusion has stopped, however, the pressure begins to decrease, indicating stress relaxation of the joint capsule walls. If such a relaxation were occurring in the posteromedial region, then receptor discharge would be expected to increase as the capsule wall became stretched. However, it can be seen that this does not occur and that discharge decreases as the pressure decreases. This would suggest that the stressrelaxation was occurring in some other part of the joint capsule not innervated by PAN rather than in the posteromedial region. Indeed it has been observed that on injection of local anaesthetic into the posteromedial region, the posterior aspect of the capsule is at first seen to swell during the injection but to regain its former shape and size on completion of the injection (Ferrell, unpublished observation). It may be that the stress-relaxation occurs in some more distensible region of the joint which is not innervated by PAN, perhaps the softer suprapatellar region which is known to be sparsely innervated. ${ }^{5}$

STEP-IN FUSIONS OF OIL

The results of these experiments indicate that, as intra-articular volume increases, so does the posteromedial pressure and the PAN discharge. The PAN discharge, however, exhibits a plateau at about 85 impulses/s, while posteromedial pressure continues to rise monotonically. The plateau in PAN discharge would seem to indicate that some limit to capsular distension had occurred, preventing further stretching of the joint receptors. If this had happened, though, the posteromedial pressure would be expected to show an enormous increase with further step infusions of fluid into the joint. It can be seen from Fig. 6, however, that this does not happen. The PAN discharge plateau also cannot be explained by some temporal limitation to capsular deformation as with the continuous infusions. In this case stepinfusions are being made and measurements are being taken 3 minutes after each step. It may be then that the PAN discharge plateau does not represent a true limit to capsular distension. Knight and Levick ${ }^{14}$ have shown that hydraulic compartmentation exists within the rabbit knee joint. Although the posteromedial and suprapatellar regions of the joint are anatomically continuous, they are not hydraulically 
continuous at low, physiological pressures. Only when a critical pressure is reached do channels linking the 2 regions open up and allow fluid communication between them. It may be that a similar situation exists in the cat knee joint. This would account for the increase in posteromedial pressure being less steep than expected while the PAN discharge is at a plateau level. Fluid may be moving from the posteromedial region into the suprapatellar region during this phase, there by limiting posteromedial distension and so producing the PAN discharge plateau and causing the posteromedial pressure increase to be less steep than expected.

Work is in progress to investigate further the theory of compartmentation in the cat knee joint and establish the effect of alteration of compartment volumes on the discharge of joint nerves.

This research was supported by the Arthritis and Rheumatism Council.

Leslie Wood is in receipt of an MRC Research Studentship.

\section{References}

1 Browne K, Lee J, Ring P A. The sensation of passive movement of the metatarso-phalangeal joint of the great toe in man. $J$ Physiol 1954; 126: 448-58.

2 Baxendale R H, Ferrell W R. The effect of knee joint afferent discharge on transmission in flexion reflex pathways in decerebrate cats. J Physiol 1981; 315: 231-42.

3 Boyd I A. The histological structure of the receptors in the knee joint of the cat correlated with their physiological response. $J$ Physiol 1954; 124: 476-88.
4 Skoglund S. Anatomical and physiological studies of knee joint innervation in the cat. Acta Physiol Scand 1956; 36 (suppl 124): 1-101.

5 Freeman M A R, Wyke B. The innervation of the knee joint. An anatomical and histological study in the cat. $J$ Anat 1967; 101: 505-32.

6 Knight A D, Levick J R. Pressure-volume relationships above and below atmospheric pressure in the synovial cavity of the rabbit knee.J Physiol 1982; 328: 403-20.

7 Myers D B, Palmer D G. Capsular compliance and pressurevolume relationships in normal and arthritic knees. J Bone Joint Surg 1972; 54B: 710-6.

8 Jayson M I V, Dixon A St J. Intra-articular pressure in rheumatoid arthritis of the knee. I. Pressure changes during passive joint distension. Ann Rheum Dis 1970; 29: 261-5.

9 Andrew B L, Dodt E. The deployment of sensory nerve endings at the knee joint of the cat. Acta Physiol Scand 1953; 28: 287-96.

10 DeAndrade J R, Grant C, Dixon A St J. Joint distension and reflex muscle inhibition in the knee. J Bone Joint Surg 1965; 47A: 313-22.

11 Ekholm J, Eklund G, Skoglund S. On the reflex effects from the knee joint of the cat. Acta Physiol Scand 1960; 50: 167-74.

12 Grigg P, Hoffman A H, Fogarty K E. Properties of GolgiMazzoni afferents in cat knee joint capsule, as revealed by mechanical studies of isolated joint capsule. J Neurophysiol 1982; 47: 31-40.

13 Levick J R. The influence of hydrostatic pressure on transsynovial fluid movement and on capsular expansion in the rabbit knee.J Physiol 1979; 289: 69-82.

14 Knight A D, Levick J R. Physiological compartmentation of fluid within the synovial cavity of the rabbit knee. J Physiol 1982; 331: 1-15.

15 Knight A D, Levick J R. Time-dependence of the pressurevolume relationship in the synovial cavity of the rabbit knee. $J$ Physiol 1953; 335: 139-52.

16 Ropes M M, Bauer W. Synovial fluid changes in joint disease. Cambridge, Mass: Harvard University Press, 1953. 